\title{
Over de problemen bij de transcriptie van Nederlandse eigennamen in het Bulgaars
}

\section{On the Transcription of Dutch Proper Names in Bulgarian}

\author{
Kaloyan Velikov
}

\begin{abstract}
This paper, 'On the Transcription of Dutch Proper Names in Bulgarian' aims at providing general rules and guidelines to be applied in a new model for the transcription of Dutch proper names in Bulgarian. The fundamental principles of translation, transliteration and transcription have been considered as the most common methods for rendering proper names from a source language into a target language with a different writing system. It is crucial that the rendering of proper names be based on the authentic articulation of the Dutch name, avoiding the imitation of its true pronunciation. The written form of the name should also be taken into account as a lasting means of communication which can affect spoken language. Such traditional versions often occurred in the past as a result of lexical translations of parts of the name or of the whole name, as well as of morphological and/or phonological adaptations. The paper shows that when rendering Dutch names into Bulgarian priority should be given to transcription over transliteration. However, the latter can be used when a sound has no equivalent in Bulgarian or when it is necessary for a name to be easily and accurately retranscribed.
\end{abstract}

\section{Keywords}

transcription; transliteration; translation of proper names; Bulgarian; Dutch 


\section{Inleiding}

Met de ontwikkeling van de politieke, economische en culturele contacten tussen Bulgarije en de Nederlanden in de laatste decennia is ook het aantal Nederlandse eigennamen dat in het Bulgaars terechtgekomen is, sterk toegenomen. Het gaat om significant meer namen dan 30 - 40 jaar geleden, wat betekent dat verregaande afwijkingen in de transcriptiepraktijk tot problemen en moeilijke situaties kunnen leiden. $\mathrm{Er}$ is meer aandacht nodig voor een passende uitspraak en schriftelijke weergave van Nederlandse persoons- en plaatsnamen in het Bulgaars, evenals van namen van kranten en tijdschriften, bedrijven, organisaties e.a.

Er werden in het verleden verschillende pogingen gedaan om voor de uitspraak en de schriftelijke weergave van eigennamen uit het Nederlandse taalgebied (meestal plaatsnamen) een bepaald transcriptiemodel op te zetten en specifieke gevallen van het Nederlandse fonetisch systeem te beschrijven. De door de Vlaamse taalwetenschappers DETREZ (1972) en QUINET-STOYANOV (1981/82) aangeboden regels voor transcriptie zijn een eerste stap, hoewel ze soms in strijd zijn met de Bulgaarse fonologie en spelling en een zo nauwkeurig mogelijke imitatie van de oorspronkelijke uitspraak voor ogen hebben. Meer duidelijkheid schept het in 1995 geformuleerde Voorschrift nr. 6 over de transcriptie en spelling van buitenlandse plaatsnamen in het Bulgaars ${ }^{l}$ en speciaal hoofdstuk 10, waarin de transcriptie van de Nederlandse toponiemen wordt vastgelegd. Dit normatieve werk biedt een beter transcriptiemodel en probeert een evenwicht tussen de klankgetrouwe weergave van Nederlandse eigennamen en de fonologische normen van de Bulgaarse taal te handhaven, ondanks de regels i.v.m. het weergeven van sommige monoftongen en diftongen en de soms eigenaardige plaats van de klemtoon (hoofd- en bijklemtoon).

Het doel van dit artikel is om op basis van moderne onderzoeksmethodes aanwijzingen en regels te geven die in aanmerking moeten genomen worden bij het creëren van een nieuw model voor de transcriptie van Nederlandstalige eigennamen in het Bulgaars.

\section{Vertaling, transliteratie of transcriptie van eigennamen}

Er zijn verschillende manieren om eigennamen uit een taal in een andere taal over te nemen. Grote moeilijkheden ontstaan er wanneer de twee talen, zoals het Bulgaars en het Nederlands, verschillende alfabetten gebruiken. Als een Nederlandse naam in een Bulgaarse tekst voorkomt, kan hij met zijn oorspronkelijke spellingwijze (met de Latijnse letters) in de tekst worden opgenomen. Op deze manier kunnen veel problemen worden voorkomen die vaak ontstaan bij de transcriptie van eigennamen vanuit het Nederlands in het Bulgaars, maar dan wordt de naam niet in de tekst geïnte-

1 Naredba nr. 6 ot 12 juni $1995 \mathrm{~g}$. za transkriptsija i pravopis na chuzhdi geografski imena na balgarski ezik (zie ook de bibliografie) 
greerd en is in feite buiten de doeltaal gehouden (DANCHEV 2010: 26). De meest gehanteerde manieren om een naam van een brontaal naar een doeltaal met een ander schriftstelsel over te brengen zijn vertaling, transliteratie en transcriptie.

\subsection{Vertaling van eigennamen}

De gebruiksfrequentie van buitenlandse eigennamen in een taal is veel lager dan die van vreemde soortnamen, die dikwijls volledig in fonetisch en morfologisch opzicht in de ontvangende taal worden geassimileerd. Leenwoorden als блок $(<N l$. blok), газ $(<N l$. gas $), к р а н$ (<Nl. kraan) e.a. zijn compleet in de Bulgaarse woordenschat geïntegreerd en alleen de taalkundigen zijn zich ervan bewust dat deze woorden van Nederlandse origine zijn. Hoewel vreemde namen makkelijker als niet-Bulgaars zullen opvallen, worden ze meestal in een vorm weergegeven die aan de Bulgaarse naamkundige praktijk is aangepast. In het verleden vonden ook vertalingen van hele namen of naamsdelen plaats die hun equivalenten in de Bulgaarse taal hadden. Zo ontstonden bij de aardrijkskundige namen veel exoniemen, die voor een traditie bij de naamweergave zorgden. Deze traditie komt vaak in conflict met de hier beschreven transcriptieregels, maar dient wel in aanmerking genomen te worden wat de Nederlandse namen betreft die al lang geleden overgenomen zijn en wier spellingwijze de doorsnee Bulgaar bekend is. Zo is het moeilijk om bij namen als Schelde en Utrecht een fonetische transcriptie toe te passen die dichter bij de oorspronkelijke uitspraak ligt. Ze worden sinds lang als [' $\left.\int \varepsilon l d ə\right]$ en ['utrext] uitgesproken en iedere poging om dit te veranderen door het aanbieden van een fonetisch trouwere variant, zou tot het ontstaan van lexicale doubletten leiden en voor verwarring zorgen.

Bij de weergave van Nederlandse eigennamen in het Bulgaars werd in het verleden de methode van complete lexicale vertaling toegepast. Bij deze methode ontstaat een leenvertaling van namen die letterlijk naar de doeltaal zijn vertaald en wier betekenis wordt behouden (cfr. KOWALSKA-SZUBERT 2013: 104). Voorbeelden zijn Noordzee

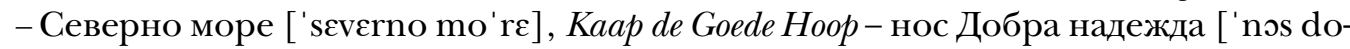
b'ra ne'dezde], De vliegende Hollander - Летящият холандец [let'jaftijat ho' landets].

Bij eigennamen die uit twee of meer componenten bestaan, werd dikwijls een andere methode gehanteerd, namelijk de lexicale vertaling van naamsdelen met morfologische en fonetische vormaanpassingen. Daardoor wordt één van de componenten compleet vertaald en de andere component of componenten zijn aan de Bulgaarse morfologische en fonologische taalnormen aangepast. Deze vertaalmethode komt frequent voor bij de weergave van Nederlandse plaatsnamen waarbij één van de bestanddelen een richting aanduidt (Oost-Vlaanderen - Източна Фландрия ['iztot/ne 'flandrija], Zuid-Holland - Южна Холандия ['juzne ho'landija]²).

2 Bij de weergave van de Nederlandse provincienamen in het Bulgaars bestaat er geen consequentie. Zo zijn bijvoorbeeld de namen Holland en Zeeland bekend als respectievelijk Холандия [hо'landija] еn Зеландия [zв'landrja], en de namen van de provincies Gelderland en Flevoland - Гелдерланд ['gelderlant] еn Флеволанд ['flevolant] - zijn getranscribeerd zonder de vormaanpassing van -land die meestal als ['landija] voorkomt. Dit 
Dezelfde vertaalmethode wordt eveneens toegepast bij de weergave van persoonsnamen met twee of meer componenten waarvan één een bijnaam is. Deze bijnaam is doorgaans met een karaktertrek of met iets speciaals verbonden wat een persoon van anderen met dezelfde naam onderscheidt. Voorbeelden daarvoor zijn bij namen van kunstenaars of historische personen te vinden (Pieter Bruegel de Oude-Питер Брьогел Стария ['piter 'brjogel 'starija], Willem de Zwijger - Вил(х)е(л)м Мълчаливи(я) ['vil(h) $\varepsilon(\mathrm{l}) \mathrm{m}$ molt $\int \mathrm{e}$ 'livi(ja)]).

Het laatste voorbeeld laat nog zien dat de voornaam van de Vader des vaderlands in het Bulgaars eveneens met zijn Duitse versie voorkomt, d.w.z. als Wilhelm 3 . Dit is ook het geval bij de voornaam van zijn zoon Maurits die als Мориц ['morits] in de Bulgaarse historiografie bekend is. De verduitsing van Nederlandse namen die al lang een plaats in het Bulgaarse lexicon hebben, is een bekend verschijnsel - het Bulgaars heeft immers meer directe contacten met het Duits dan met het Nederlands gehad. Precies via deze taal zijn veel Nederlandse persoonsnamen en vooral plaatsnamen in het Bulgaars terechtgekomen. Voorbeelden daarvoor zijn Leiden en Eindhoven die in het Bulgaars met het Duitse substituut van de tweeklank / $\varepsilon \mathrm{i} /$ worden weergegeven - respectievelijk als ['lajden] en ['ajndhoven]. Invloed van andere talen is ook bij de weergave van namen als Brugge (Bulg. Брюж [brju3] vanuit het Frans Bruges ['ьву:3]) of Den Haag (Bulg. Хara ['hage] vanuit het Russisch Гaaza ['ga:ge]) te merken. Dit laat ons concluderen dat in het Bulgaars veel exoniemen zijn ontstaan via een "grotere" tussentaal, waardoor het tegenwoordig moeilijk is om de juiste transcriptie toe te passen, hoewel er in laatste tijd zulke pogingen worden gedaan ${ }^{4}$. Een verdere moeilijkheid ontstaat doordat van de bovengenoemde namen nieuwe woorden werden afgeleid (Leidse fles - Bulg. 'лайденска стъкленица' ['lajdenske stəkle'nitse], Brugse kant-Bulg. ‘брюжка дантела' ['brjuzke den'tele]) en een verandering van de al lang gebruikte naam zou tot een breuk in de semantische relatie tussen deze naam en het afgeleide woord leiden.

Zeer productief bij de morfologische vormaanpassing blijkt het Bulgaarse suffix -ski (vrouwelijk -ska) te zijn. Daarmee worden adjectieven gevormd die van een naam afgeleid zijn en verbondenheid of afkomst aanduiden (Nederlandse Antillen Нидерландски Антили [nıder'lan(t)ski an'tıli], Desiderius Erasmus (van Rotterdam) Еразъм Ротердамски [عr'azəm 'roterdamski], Beatrix van Oranje - Беатрикс Оранска ['beatriks o' ranska]).

is te wijten aan het feit dat de namen Holland en Zeeland veel eerder en frequenter in de Bulgaarse taal werden gebruikt dan die van Gelderland en de nieuwste provincie Flevoland. Holland wordt vaak in plaats van Nederland als naam van de hele staat gebruikt en de naam van Zeeland wordt automatisch met die van Nieuw Zeeland - ['nove ze' landija] - geassocieerd. Bij de naam van provincie Friesland werd het bestanddeel -land compleet weggelaten waardoor de Bulgaarse variant Фризия ['frızija] is ontstaan (waarschijnlijk getranscribeerde variant van de Latijnse vorm van de naam - Frisia).

3 Deze historische naam komt in het Bulgaars ook met de Engelse variant ['wilım] voor als het om de stadhouder Willem III gaat die vanaf 1689 over Engeland en Ierland begon te regeren.

4 De naam Brugge komt steeds vaker met de transcriptievorm ['brjuge] voor, die dichter bij de oorspronkelijke Nederlandse vorm staat dan bij de Franse variant. 


\subsection{Transliteratie}

Een andere manier om een tot een bepaalde taal horende naam in een andere weer te geven is de transliteratie (van Lat. trans (naar de andere kant) + littera (letter)). Door middel van deze methode worden grafemen of eenheden van het schriftsysteem van de brontaal in eenheden van het schriftsysteem van de doeltaal omgezet.

De begrippen letter en grafeem komen niet altijd overeen. Hoewel de schrijfsymbolen in de talen die het Latijnse alfabet gebruiken, min of meer dezelfde zijn, hebben ze vaak als eenheden van verschillende schriftsystemen een andere functie. Bijvoorbeeld wordt de [S]-klank in het Engels met de lettercombinatie $<$ sh $>$ geschreven, in het Duits met $<\mathrm{sch}>$, in het Frans met $<\mathrm{ch}>$, in het Pools met $<\mathrm{sz}>$ en in het Nederlands met $\langle\mathrm{sj}\rangle$. In het Bulgaarse alfabet is er daarvoor één letter $\langle\omega\rangle$. Met andere woorden kunnen combinaties van letters op dezelfde manier als één letter functioneren, d.w.z. als één eenheid of grafeem (DANCHEV 2010: 27).

Het feit dat de eigenaardigheden van het Nederlandse klanksysteem onder de taalgebruikers van het Bulgaars onbekend zijn, leidt tot de neiging om bij de naamweergave de voorkeur aan de transliteratie boven de transcriptie te geven. Daardoor ontstaan soms zeer vreemde naamvarianten, die dikwijls in tegenspraak zijn met de Bulgaarse spellingregels of ver van de oorspronkelijke uitspraak liggen.

Voorbeelden hiervan zijn te vinden in namen waarin een dubbel geschreven klinker in gesloten lettergreep voorkomt. Deze verdubbeling is vaak in de Bulgaarse orthografie van Nederlandse namen te zien, waarschijnlijk met het idee om de lengte van de klinker te behouden ( Van Praag - Ван Праaаr, Ossevoort - Осевоopт, Heerenveen - Хеepeнвеeн). Het inheemse Bulgaarse vocaalsysteem kent eigenlijk geen lange en korte klinkers en zo geschreven zouden de dubbel geschreven klinkers in de gesloten syllabe als twee enkele uitgesproken worden (zoals in de Bulgaarse familienaam Пеeв ['pecv]) (PARASHKEVOV 2006: 110). Een bewijs van het bovengenoemde is ook de uitspraak van de ontleende soortnaam краaл $(<N l$. kraal) die in het Bulgaars uit twee lettergrepen bestaat, waarbij de [a]'s als twee aparte klinkers worden uitgesproken. Dit is een verschil met de uitspraak van hetzelfde leenwoord in het Pools, waarvan de Nederlandse spellingwijze wordt bewaard, maar „de uitspraak van de klank de Poolse is, dus [a]" (KOWALSKA-SZUBERT 2013: 133). De Bulgaarse taal laat dergelijke uitzonderingen niet toe, wat ook een reden is om meer aandacht aan de weergave van vreemde woorden en namen te besteden en daardoor afwijkingen in de authentieke uitspraak te vermijden.

De Nederlandse diftongen schijnen bij hun weerhave in het Bulgaars nog meer problemen te veroorzaken. De spellingsonderdelen van een klinkerdigraaf worden in menig geval als aparte klanken beschouwd en op deze manier getranslitereerd (Wout - Воут [vout], Kluivert-Клуиверт ['kluivert]). Bij sommige namen kunnen zelfs veel varianten ontstaan die in mindere of meerdere mate van de authentieke Nederlandse uitspraak verschillen ${ }^{5}$. Een zo dicht mogelijke benadering van de oorspronkelijke

$5 \quad$ Zie ook 2.3.2. 
uitspraak van de naam is immers één van de principes waarop de methodes van de naamweergave gebaseerd moeten worden (ANDREYCHIN/VAGLENOV 1974: 10). Dit is de reden waarom transcriptie steeds vaker wordt gebruikt in tegenstelling tot transliteratie.

Transliteratie moet bij de weergave van Nederlandse namen in het Bulgaars echter niet geheel uitgesloten worden. Deze kan en moet toegepast worden wanneer klanken als de stemhebbende velare fricatief $[\gamma]$ of de labio-dentale approximant [v] worden vervangen. Die hebben geen fonetische equivalenten in de Bulgaarse taal en in dat geval wordt doorgaans het principe van vormovereenkomst gebruikt (Gent - Гент [gent], Waterloo - Ватерло ['vaterlo] $)^{6}$. Hetzelfde principe wordt gehanteerd wanneer de 'doffe e' of sjwa $(/ \curvearrowright /)$ in het Bulgaars wordt omgezet (Vermeer - Вермер [ver'mer], De Jansen - Де Янсен [de 'jansen], Winsum - Винсюм ['vinsym]) 7 .

Transliteratie komt ook van pas als het nodig is een eigen- of soortnaam op zo'n manier weer te geven dat hij makkelijk en eenduidig gehertranscribeerd zou kunnen worden - bij persoonsgegevens in documenten, titels van wetenschappelijke bijdragen etc.

De kwestie in hoever de methode van transliteratie bij de naamweergave moet worden toegepast, is niet helemaal duidelijk. Hierbij dient een juiste verhouding tussen de geschreven en gesproken taal gevonden te worden. Hoewel bij de naamweergave de authentieke uitspraak in de brontaal in acht wordt genomen, moet altijd rekening worden gehouden met de traditionele geschreven vorm van de naam, omdat die ook een belangrijke rol als communicatiemiddel speelt. Het is zelfs een middel met duurzaam karakter, dat in veel gevallen de gesproken taal beïnvloedt (DANCHEV 2010: 31).

\subsection{Transcriptie}

Transcriptie (van Lat. transcribere - overschrijven) is het fonetisch overbrengen van namen en woorden in een ander teken- of spellingsysteem. Naargelang er woorden binnen een taal worden getranscribeerd (in woordenboeken, bij het talen leren etc.) of van een taal in een andere taal, onderscheiden we binnentalige en tussentalige transcriptie. De laatste wordt door (BARCHOEDAROV 1975) ook vertaaltranscriptie genoemd.

\footnotetext{
$6 \quad$ Zie ook 2.3.1.

7 Sommige taalwetenschappers stellen voor de klank / / / binnen in het woord met de Bulgaarse letter $<\mathrm{b}>$ weer te geven, en aan het eind van het woord met de letter < a > (cfr. DETREZ 1972 en QUINET-STOYANOV $1981 / 82)$. Op deze manier zou de getranscribeerde naam in hogere mate de authentieke uitspraak weergeven en het zou eveneens makkelijker voor de taalgebruikers van het Bulgaars zijn om de juiste plaats van de klemtoon in de Nederlandse naam te bepalen (/sxevəningən/ i.p.v. /sxeveningen/ waarbij het duidelijk wordt op welke $<\mathrm{e}>$ de klemtoon valt). De Bulgaarse halfopen klinker $/ \mathrm{b} /$ als pendant van de eveneens achter in de mond gevormde open klinker /a/ kan echter ook beklemtoond zijn, wat tot verwarring zou kunnen leiden bij de bepaling van de accentplaats in de naam. Door de hoge frequentie van de sjwa in Nederlandse woorden onstaat het gevaar dat de gehele fonetische gestalte van het Nederlands verkeerd weergegeven zou kunnen worden als de klank / / overal met $<\mathrm{b}>$ wordt gesubstitueerd. Daarom is het praktischer als bij sjwa het letterlijke equivalent grofweg wordt getranslitereerd. Een uitzondering is het achtervoegsel $-l i j k$ waarbij $/ \mathrm{\curvearrowright} / \mathrm{met} / \mathrm{b} / \mathrm{kan}$ worden vervangen.
} 
Het succesvolle onderzoek van de vele problemen die bij de tussentalige transcriptie van Nederlandse namen in het Bulgaars ontstaan, is grotendeels afhankelijk van de aanwezigheid van een duidelijk en wetenschappelijk gemotiveerd systeem voor binnentalige transcriptie in de brontaal. Daarbij moet dit onderzoek niet alleen op de extralinguïstische factoren worden gebaseerd die hierboven al werden besproken (als vertaling van namen en traditie). Van groot belang hiervoor is ook de vergelijkende analyse van de foneeminventaris van de twee talen die met het oog op de klankverschillen wordt gemaakt. Zulke verschillen zijn zowel bij de consonanten als bij de vocalen te zien; daarom worden de twee groepen van klanken apart geanalyseerd.

\subsubsection{De consonanten}

De meeste Nederlandse medeklinkers hebben hun vaste cyrillische equivalent in het Bulgaarse alfabet en kunnen zonder moeite daardoor worden vervangen. Dit zijn $\langle\mathrm{b}\rangle,\langle\mathrm{d}\rangle,\langle\mathrm{f}\rangle,\langle\mathrm{k}\rangle,\langle\mathrm{l}\rangle,\langle\mathrm{m}\rangle,\langle\mathrm{n}\rangle,\langle\mathrm{p}\rangle,\langle\mathrm{r}\rangle,\langle\mathrm{s}\rangle$ en $\langle\mathrm{t}\rangle$. Ze worden gesubstitueerd respectievelijk door $\langle\sigma\rangle,\langle\mathrm{A}\rangle,\langle\mathrm{\phi}\rangle,\langle\mathrm{H}\rangle,\langle\mathrm{J}\rangle,\langle\mathrm{M}\rangle,\langle\mathrm{H}\rangle,\langle\mathrm{\Pi}\rangle,\langle\mathrm{p}\rangle,\langle\mathrm{c}\rangle$ en $\langle\mathrm{T}\rangle$. Tot deze groep behoren ook de twee letters $\langle\mathrm{q}>$ en $\langle\mathrm{x}\rangle$ die vooral in namen en woorden van buitenlandse origine voorkomen. Hun substituten zijn $<$ KB $>$ en $<$ KC $>$ (Rasquert - Раскверт, Stox-Стокс). De overige consonanten hebben geen of meer dan één fonetisch equivalent en moeten als bijzondere gevallen nader beschouwd worden.

De derde letter van het Nederlandse alfabet $<\mathrm{c}>$ wordt in de meeste gevallen juist met de Bulgaarse medeklinkers $<\mathrm{c}>$ of $<\mathrm{K}>$ weergegeven (Vincent - Винсент, Francien - Франсин, Cadzand - Катзанд). Zelden wordt de $<\mathrm{c}>$ door de affricaat /ts / vervangen die in het Bulgaars met de letter $<ц>$ wordt geschreven (Cees Nooteboom - Цес Нотебом ${ }^{8}$, Topsport Centrum - Топспорт Центрум).

Met verschillende letters wordt ook de stemhebbende velare fricatief $[\gamma]$ gesubstitueerd, die geen fonetisch equivalent in het Bulgaarse klanksysteem kent. Deze consonant wordt met $\langle\Gamma\rangle-$ de stemhebbende tegenhanger van de Bulgaarse $/ \mathrm{k}$ / - of met de stemloze velare fricatief /x/ omgezet (Van Gogh - Ван Гог, Groningen Гронинген, Guido Gezelle - Хидо Хезеле, T. Dragt - Т. Драхт). Het probleem met de weergave van deze klank werd al door menig taalwetenschapper onderzocht (cfr. DETREZ (1972), QUINET-STOYANOV (1981/82), PARASHKEVOV (2006)) en allemaal zijn ze van mening dat het enige correcte substituut van $[\gamma]$ de Bulgaarse $<\Gamma>$ moet zijn. Argumenten in deze richting worden zowel in de traditie (Gent - Гент, graaf-Bulg. 'граф') als ook in het principe van vormovereenkomst gezocht die eveneens bij de weergave van de Oekraïense en de Wit-Russische letter $<r>$ in het Bulgaars wordt toegepast. De laatste wordt ook als stemhebbende velare fricatief gearticuleerd en heeft geen Bulgaars fonetisch equivalent, maar wordt in het Bulgaars met de

8 De roepnaam Cees van de Nederlandse schrijver en journalist, geboren als Cornelis Johannes Jacobus Maria Nooteboom, wordt op verschillende manieren in het Bulgaars getranscribeerd. Behalve de reeds genoemde variant Цес [tses] die bij de vertaling van zijn boek Een lied van schijn en wezen in het Bulgaars nog te zien is, komen ook de volgende transcriptievarianten voor: Цеес [tse:s], Кеес [ke:s] en Ceеc [se:s]. 
letter $\langle\mathrm{r}\rangle$ weergegeven en als $[\mathrm{g}$ ] uitgesproken (ANDREYCHIN/VAGLENOV 1974: $37 / 45)$. Sporadisch wordt $[\gamma]$ door de Bulgaarse affricaat $\langle \%>(/ 3 /)$ vervangen wanneer een naam die in meerdere talen voorkomt, onder de Bulgaren beter bekend is in zijn vreemde uitspraak (Geraard - Жерард [3є'rart] i.p.v. Герард [ge'rart]).

Met de letter $\langle\mathrm{x}\rangle$ wordt een andere Nederlandse klank weergegeven, namelijk de glottale /h/ (Нoorn - Хорн, Hals - Халс). Deze medeklinker heeft geen gelijkwaardig substituut in het fonetisch systeem van het Bulgaars en komt geschreven ook voor in combinatie met andere consonanten, waardoor hij zijn fonetische waarde verliest. Bij namen als Theo, Rhea, Van Gogh wordt de glottale klank niet uitgesproken en bij de weergave in het Bulgaars valt hij weg (Bulg. Тео, Реa, Ван Гог). Dit is echter niet het geval als de $/ \mathrm{h} /$ een deel van de digrafen $<\mathrm{ch}>$ en $<\mathrm{ph}>$ uitmaakt, waardoor een an-

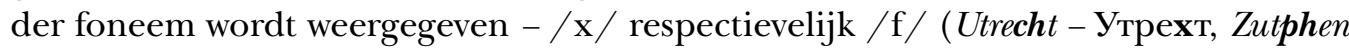
- Зютфен). Bij namen en woorden met een vreemde herkomst kan $<\mathrm{ch}>$ ook met $/ \mathrm{t} \int /, / \mathrm{J} /$ en $/ \mathrm{k} /$ worden weergegeven en respectievelijk met de Bulgaarse letters $<\mathrm{\varphi}\rangle,<$ шा $>$ en $<\mathrm{K}>$ geschreven (chat - чат, chauffeur - шофьор, Chris - Крис). Van groot belang bij de weergave van zulke digrafen is de kennis van de syllabiseringsprincipes in het Nederlands om de morfeemgrenzen in de naam of in het woord op een juiste manier te kunnen bepalen. Als de consonanten die in principe een digraaf kunnen vormen deel van twee naast elkaar staande syllabes uitmaken, dan zijn het twee aparte medeklinkers en niet als één klank gearticuleerd. Ze worden eveneens met twee aparte grafemen weergegeven (Berghuizen - Бергхьойзен, Beethoven - Бетховен, Staphorst - Стапхорст, Zuidhorn - Зьойдхорн).

Dezelfde regel komt ook van pas bij dubbel geschreven medeklinkers die normaliter alleen met één letter worden gesubstitueerd (Rotterdam - Ротердам, Middelburg - Миделбург, Dokkum - Докюм, maar Beekkant - Беккант). Het is belangrijk om toe te voegen dat deze dubbele consonanten geschreven worden om een gesloten lettergreep aan te duiden en dus geen geminaat zijn.

Beïnvloed door de moderne methodes bij de Bulgaarse transcriptie van Duitse namen wordt de combinatie van de consonanten $/ \mathrm{d} / \mathrm{en} / \mathrm{t} /$ aan het eind van de naam alleen met het grafeem $\langle\mathrm{T}\rangle$ weergegeven, anders dan de traditionele schrijfwijze bij sommige Nederlandse namen (Aerdt - Aрт, Berndt - Бернт, maar Rembrandt - Рембранд).

De Duitse invloed is ook te merken bij de weergave van de consonantengroep $<\mathrm{sch}>$ die dikwijls door $/ \mathrm{J} /$ wordt gesubstitueerd (Den Bosch - Ден Бош [den 'bof], Schiphol- Шипхол ['Jiphol]), evenals bij de transcriptie van namen die met /v/ of /z/ beginnen. Vanwege de verstemlozing van deze twee fricatieven, meestal aan het begin van het woord in de Noord-Nederlandse ${ }^{9}$ uitspraak (KOOIJ/VAN OOSTENDORP 2003: 62/63), worden namen uit dit (deel van het) taalgebied soms met de stemloze fricatief /f/ en de stemloze affricaat /ts / weergegeven (Vlissingen- Флисинген ['flisingen], Van Vliet - Ван Флит [van'flit], Zeist - Цайст [tsajst], Zutphen - Цутфен ['tsutfen]). Daardoor ontstaan ook nieuwe naamvarianten, die naast de klankgetrouw

$9 \quad$ In tegenstelling met het Zuid-Nederlands of Belgisch-Nederlands 
weergegeven naam bestaan (zoals bij Zutphen - Зютфен of Цутфен). Tосh is het belangrijk hier toe te voegen dat in de laatste tijd de medeklinkers $/ v /$ en $/ \mathrm{z} /$, evenals de trigraaf $<\mathrm{sch}>$ steeds vaker op een klankgetrouwe manier worden getranscribeerd waardoor de „verduitsing” van de Nederlandse namen stilaan verdwijnt.

Problemen zijn er ook bij de weergave van Nederlandse namen waarin de glijklank (approximant) $/ \mathrm{j} /$ voorkomt. Deze klank wordt in het algemeen met de Bulgaarse letter $<$ Й $>$ weergegeven (Jeroen - Йерун, Joris - Йорис), maar in combinatie met bepaalde klinkers kunnen daarvoor ook andere grafemen gebruikt worden $(\mathrm{ja} / \mathrm{jaa}=$ $<$ я $>-$ Jan - Ян, Jaар - Яп, ju $/$ joe = <ю $>-$ Juliana - Юлиана, Joeke - Юке). Hoewel er spellingregels zijn die nauwkeurig bepalen hoe de $<\breve{h}>$ volgens de Bulgaarse orthografie gebruikt zou moeten worden, komen er vaak onjuistheden bij de transcriptie van zulke namen voor. Voorbeelden zijn te vinden in de pogingen om de verzachting van de consonant voor $\mathrm{de} / \mathrm{j} /$ weer te geven als de lettercombinatie $<\mathrm{je}>$ binnen in de naam na een medeklinker voorkomt (Laurentien van Oranje - Лаурентин ван Оранйе), waarbij er van de traditie afwijkende varianten ontstaan ${ }^{10}$. Om dit te vermijden wordt de approximant gewoon weggelaten en de consonant daarvoor wordt niet palataal gearticuleerd (Ankje - Анке ['anke], Boompjesdijk - Бомпесдейк ['bompes$\mathrm{d} \varepsilon \mathrm{ik}]$ ), tenzij deze consonant een $/ \mathrm{s} /$ of $/ \mathrm{t} /$ is waarmee $\mathrm{de} / \mathrm{j} /$ nieuwe klanken vormt $-/ \mathrm{S} /$ respectievelijk $/ \mathfrak{t} /$ (Guusje - Гюше, Aaltje - Алче). Er moet ook in acht genomen worden dat de Bulgaarse klinkers / $/$ / $[\mathrm{ja}])$, /ю/ ([ju]) en de lettercombinatie $<$ йо $>$ ([jo]) die na een medeklinker als $<$ ьo $>$ voorkomt (Arjo - Apьo), gedepalataliseerd worden wanneer ze na de fricatieven $/ \mathrm{S} /$ en $/ 3 /$, zoals na de affricaat $/ \mathfrak{d} /$ verschijnen en respectievelijk met de Bulgaarse letters $\langle\mathrm{a}\rangle,\langle\mathrm{y}\rangle$ en $\langle\mathrm{o}\rangle$ worden weergegeven (Sjaak - Шак, Jules - Жул, Eltjo - Елчо).

Hoewel de /j/ bij de diftong / ei/, zoals bij de semi-diftongen /aai/, /ooi/ en / oei / grafisch niet wordt weergegeven, worden deze over het algemeen gezien als combinaties van een klinker met / $\mathrm{j}$ / (VAN OOSTENDORP: 2000). Bij hun weergave in het Bulgaars treedt de $<$ $>$ al als schriftelijk subtituut op (Maaike - Майке). Dit komt ook bij de andere approximant /w/ voor die bij de Bulgaarse transcriptie van de semi-diftong / eeuw / door de Bulgaarse $<\mathrm{B}>$ wordt vervangen, in het geval hij door een klinker wordt gevolgd (Leешwarden - Леуварден, Van Meешwen - Ван Меувен). Dit verschijnsel ontstaat om klinkerstapeling te vermijden. In de andere gevallen wordt de /eeuw/ alleen met de lettercombinatie <ey> weergegeven (De Leeuw - Де Лey).

De kwestie over de juiste weergave van de glijklank /w/ in het Bulgaars heeft in het verleden verschillende meningen opgeleverd. Volgens DETREZ (1972) en QUINET-STOYANOV (1982) moet deze klank, die doorgaans als labio-dentale [v] of bilabiale $[\mathrm{w}]$ wordt gearticuleerd, met de Bulgaarse oe-klank $(/ \mathrm{y} /)$ worden weergegeven. Ten opzichte van de fonologische correctheid schijnt dit voorstel logisch, maar als de approximant door de lange klinker /oe / wordt gevolgd (bijvoorbeeld in de naam

10 Volgens de Bulgaarse orthografie komt de letter $<\breve{h}>$ nooit na een medeklinker voor. In de getranscribeerde naam van de Nederlandse princes $L$. van Oranje hebben wij niet alleen met een afwijking in de spellingregels te maken, maar ook met het negeren van de traditie bij de weergave van de dynastienaam Van Oranje, die in het Bulgaars als Орански /oranski/of Оранска /oranska/ wordt weergegeven (zie 2.1.) 
Van de Woestijne) ontstaan er problemen. In dat geval zou deze naam in het Bulgaars met twee $\langle\mathrm{y}\rangle$ als ${ }^{*}$ Устейне worden geschreven, wat niet typisch voor de Bulgaarse schrijfwijze is en evenmin makkelijk voor de articulatie (zie 2.2.). Een betere variant is de substitutie van de glijklank / w / door de Bulgaarse medeklinker /B/ ([v]). Precies deze letter wordt gebruikt bij de weergave van Nederlandse eigen- en soortnamen die al lang een deel van de Bulgaarse woordenschat uitmaken (waterlijn - ватерлиния ['vaterlinija], wimpel - вимпел ['vimpel], Willem - Вилем ['vılkm]). Hetzelfde substituut is ook bij andere talen te vinden die het cyrillische schrift gebruiken (Rus. Вильгельм, Oekr./W.Rus. Вільгельм, Srb. Вилем). De traditionele weergave van /w/ met de Bulgaarse / B / en het gebruik van het gelijke grafeem in andere Slavische talen laten ons concluderen dat de approximant /w/ in het best met /B/ kan worden getranscribeerd.

\subsubsection{De vocalen}

De meeste taalkundigen zijn van mening dat het Nederlands „ongeveer 40 fonemen” heeft (NEIJT 1991: 156). Volgens (DIRVEN/VERSPOOR 2001: 126-127) is hun aantal 46, waarbij ze 14 klinkers, 9 diftongen en 23 medeklinkers onderscheiden, d.w.z. dat de som van de klinkers en de diftongen gelijk is aan het aantal medeklinkers. Dit is een groot kwalitatief verschil met de foneeminventaris van het Bulgaars dat 39 consonanten ${ }^{11}$ en maar 6 vocalen telt (TILKOV/BOYADZHIEV 1977: 45). Daardoor wordt het duidelijk dat het aantal fonemen in de beide talen bijna gelijk is, maar ze verschillen veel op het gebied van de vocalen. Dit veroorzaakt problemen, die zowel bij de weergave van de Nederlandse korte en lange klinkers, als ook van de tweeklanken te zien zijn.

Over het algemeen hebben de korte Nederlandse vocalen hun vaste substituut in het Bulgaarse vocaalsysteem. Zo worden de klinkers $/ \mathrm{I} /, / \mathrm{o} /, / \varepsilon /$ en $/ \mathrm{a} /$ altijd met de letters $\langle$ u $\rangle,\langle 0\rangle$, $\langle$ e $\rangle$ en $\langle$ a $\rangle$ weergegeven. Diverse varianten komen voor bij de weergave van de klank $/ \mathrm{y} /$. In namen die sinds lang een deel van de Bulgaarse taal uitmaken (bv. Limburg), wordt de korte klinker als [u] opgevat en met de letter $\langle\mathrm{y}\rangle$ weergegeven (Bulg. Лимбург). In de laatste jaren verschenen echter in de gedrukte en elektronische media, zoals in sommige boekvertalingen, naamvarianten waarbij de /y / met de Bulgaarse letter $<ю>$ wordt weergegeven (M. Rutte - М. Рюте, Hugo Claus - Хюго Клаус). Dit substituut van $<\mathrm{u}>$ staat akoestisch dichter bij de uitspraak van de vocaal en dient bij de transcriptie van Nederlandse namen toegepast te worden. Alle andere substituten als [y] en [йо] (resp. [ьо] ${ }^{12}$ ) zijn niet adequaat voor een klankgetrouwe weergave en moeten niet gebruikt worden, behalve in traditionele naam-

11 Samen met de gepalataliseerde pendanten

12 Deze variant van transcriptie van de korte klinker $<\mathrm{u}>$ komt voor in Naredba $\mathrm{nr}$. 6 ot 12 juni $1995 \mathrm{~g}$. za transkripcija i pravopis na chuzhdi geografski imena na balgarski ezik, p. 20 
varianten of afgeleide namen (naamsdelen) daarvan (Van den Burg - Ван ден Бург, Limburger $^{13}$ - лимбургер).

Zoals eerder vermeld (zie 2.2.) kent het inheemse Bulgaarse vocaalsysteem de oppositie lange - korte klinkers niet. Dit veronderstelt veel fouten bij de weergave van de lange Nederlandse vocalen. Naast de overbodige verdubbeling van de letters $<a>$, $\langle\mathrm{o}\rangle,\langle\mathrm{e}\rangle$ en $\langle\mathrm{u}\rangle$ bij hun weergave in gesloten lettergrepen ${ }^{14}$, worden de onderdelen van de klinkers $<$ oe $>$ en $<$ eu $>$ vaak als twee aparte klinkers beschouwd en op deze manier weergegeven (Boer- Боер ['boєr], Van der Meulen - Ван дер Меулен [van der me'ulen]).

Bij de substitutie van de Nederlandse diftongen in het Bulgaars bestaat er eveneens geen consequentie, waardoor er veel varianten onstaan. Zo worden de tweeklank $<$ ui $>$ en de (oudere) spellingvarianten $\langle$ uy $>/<u$ uij $>$ in het Bulgaars op acht verschillende manieren weergegeven, t.w. vooral als $\langle$ ой $>$, $<$ уй $>$, $<$ ии $>$ en zelden met $<$ юй $>$, $<$ ай $>,<$ юи $>$, <ay $>$ en met het klankgetrouwe substituut (na een medeklinker) $<$ ьой $>$. Deze varianten van transcriptie zijn bij de weergave van namen van politici en voetbalspelers als $H$. Van Rompuy, P. Kluivert, D. Kuijt, K. De Bruyne e.a. te vinden die in de laatste jaren in Bulgarije bekend zijn geworden. In Nederlandse namen die sinds lang in de Bulgaarse taal zijn binnengedrongen komen echter deze varianten niet voor bijvoorbeeld de familienaam van Johan Cruyff wordt in het Bulgaars alleen als Kрой $\oint$ [kroif] getranscribeerd. Het substituut <ой $>$ is trouwens een passende variant van transcriptie in het begin van de naam (Uilen - Ойлен). Zo wordt de lettercombinatie $<$ йой $>$ vermeden, die niet typisch voor de Bulgaarse uitspraak is. Binnen in de naam dient de diftong / œy/ echter met <ьой $>$ weergegeven te worden om de authentieke Nederlandse articulatie van de tweeklank te kunnen handhaven.

De tweeklank /ij/ wordt ook op verschillende manieren weergegeven. Dikwijls wordt hij getranslitereerd (Rijkaard - Рийкард ['ri:kart], Nijmegen - Ниймеген ['ni:megen]) of als [aj] getranscribeerd (Van Dijk - Ван Дайк [van dajk], KlapwijkКлапвайк ['klapvajk]). Deze substitutie met [aj] wordt ook bij de weergave van de diftong / $\varepsilon$ i/ gebruikt, beïnvloed door de transcriptie van de gelijke tweeklank in het Duits (Leiden - Лайден ['lajden], Eindhoven - Айндховен ['ajndhoven]) ${ }^{15}$. Tegenwoordig is er echter een tendens om deze diftongen op een manier weer te geven die dichter bij de authentieke uitspraak staat, d.w.z. als [عi]. Zo'n tendens wordt ook bij de substitutie van de tweeklank / au/ vastgesteld, die als <ou $>$ wordt geschreven. De diftong wordt doorgaans met de Bulgaarse letter $<y>$ of de combinatie $<$ ay $>$ getranscribeerd, afhankelijk van de articulatie van de tweeklang in de Nederlandse naam (Апои - Анук, Van Houten - Ван Хаутен). In 2.2. wordt het duidelijk dat de onderdelen van deze klinkerdigraaf vaak als aparte klanken worden gesubstitueerd (Kout - Коут [kout]), maar recente transcriptievarianten laten wel zien dat de tweeklank / $\mathrm{au} /$ steeds vaker met het juiste substituut wordt weergegeven. Deze positieve trend is

13 Soort kaas

14 Zie voorbeelden in 2.2.

15 Zie ook 2.1. 
enerzijds een resultaat van de intensivering van de mondelinge contacten tussen de Bulgaren en de Nederlandstaligen, waarbij de authentieke uitspraak van de Nederlandse namen vaker te horen valt, en anderzijds - van het werk van sommige taalwetenschappers (met name de germanist B. Parashkevov), die proberen zo veel mogelijk passende varianten bij de transcriptie van Nederlandse namen aan te bieden en te verspreiden.

\section{Conclusie}

Bij de weergave van Nederlandse eigennamen in het Bulgaars dienen een paar leidende principes in aanmerking genomen te worden om een optimaal transcriptiemodel te creëren. Bovenaan staat de klankgetrouwe weergave, gebaseerd op de authentieke uitspraak van de Nederlandse naam, waarbij er echter geen imitatie van de originele uitspraak wordt nagestreefd. Tevens dient de traditionele geschreven vorm van de naam in acht genomen te worden, omdat hij ook een belangrijke rol als duurzaam communicatiemiddel speelt, dat in veel gevallen de gesproken taal beïnvloedt. Deze traditionele naamvarianten zijn in het verleden o.a. ontstaan als gevolg van lexicale vertalingen en/of vormaanpassingen.

Bij de weergave van namen moet de voorkeur worden gegeven aan transcriptie boven transliteratie, maar die laatste kan goede diensten bewijzen wanneer de te substitueren klank geen equivalent in het Bulgaars heeft of de naam makkelijk en eenduidig gehertranscribeerd zou moeten worden.

Deze hoofdprincipes laten ons de conclusie trekken dat de Bulgaarse transcriptie van Nederlandse namen een zeer complex werk is, dat door veel factoren wordt beinvloed. De beslissing welke daarvan toe te passen is, dient bij elke naam apart genomen te worden.

\section{Bibliografie}

ANDREYCHIN, L., VAGLENOV, M. (1974): Izgovor i transkriptsija na chuzhdi imena v balgarskija ezik, Nauka i izkustvo, Sofia.

BARCHOEDAROV, L. (1975): Jazyk i perevod, Mezhdunarodnije otnoshenija, Moskou.

DANCHEV, A. (2010): Balgarska transkriptsija na anglijski imena, Iztok-Zapad, Sofia.

DETREZ, R. (1972): Izgovor i transkriptsija na niderlandskite imena na balgarski ezik, Balgarski ezik, 4, 344-347.

DIRVEN, R.,VERSPOOR. M. (2001): Cognitieve inleiding tot taal en taalwetenschap, Leuven/ Leusden, Acco.

KOOIJ, J., OOSTENDORP, M. van (2003): Fonologie. Uitnodiging tot de klankleer van het $\mathrm{Ne}-$ derlands, Amsterdam Univ. Press, Amsterdam.

KOWALSKA-SZUBERT, A. (2013): Polder, lakmus en kordzik. Nederlandse lexicale ontleningen in het hedendaags Pools, Wroclaw.

NEIJT, A. (1991): Universele fonologie, Foris Publications, Dordrecht. 
OOSTENDORP, M. van (2000): Klanken in een mensenhoofd en in de natuur. http:/ / www.meertens.knaw.nl/medewerkers / marc.van.oostendorp/propedeuse/1.klanken.html (geraadplegd tussen $15 / 01 / 15$ en $31 / 03 / 15)$.

PARASHKEVOV, B. (2006): Nerazborii s njakoi niderlandski imena, Balgarski ezik, LIII, 2006/4, IK EMAS, 110-112.

QUINET-STOYANOVA, C. (1981): Spisak na transkribiranite geografski imena na Niderlandija, Glavno upravlenie po geodezija, kartografija i kadastar. Sofia.

QUINET-STOYANOVA, C. (1982): Spisak na transkribiranite geografski imena ot Belgija, Glavno upravlenie po geodezija, kartografija i kadastar. Sofia.

TILKOV, D., BOYADZHIEV, T. (1977): Balgarska fonetika, Nauka i izkustvo, Sofia.

Glava deseta. Pravila za transkriptsija i pravopis na niderlandskite geografski imena (nova - DV, br. 106 ot 1995 g.), In: Naredba nr. 6 [...].

Naredba nr. 6 ot 12 juni 1995 g. za transkripcija i pravopis na chuzhdi geografski imena na balgarski ezik, izdadena ot Ministerstvoto na teritorialnoto razvitie i stroitelstvoto; Obn. DV. br. 60 ot 4 juli 1995 g., dop. DV. br. 72 ot 15 avgust 1995 g., dop. DV. br. 106 ot 5 dekemvri 1995 g., dop. DV. br. 4 ot 15 januari $1999 \mathrm{~g}$.

ass. Kaloyan Velikov / k.velikov@uni-vt.bg

Universiteit "St. Cyril en Methodius", Departement "Germanistiek en neerlandistiek",

Faculteit der Letteren, T. Tarnovski str. 2,

5000 Veliko Tarnovo, Bulgaria 
